\title{
Can blockchain be a strategic resource for ODL?: a study
}

\author{
Nikhil Kant \\ Research Scholar, School of Management Studies, IGNOU, New Delhi, India, and \\ Kumari Anjali \\ Research Scholar, School of Sciences, IGNOU, New Delhi, India
}

\begin{abstract}
Purpose - The purpose of this paper is to examine the hitherto unexplored strategic potentialities of blockchain as an intangible resource for open and distance learning (ODL) to attain and sustain competitive advantage by creating a more learner centric learning ecosystem.

Design/methodology/approach - Research design included review of the literature, desk research and case analyses to conduct this study so that the hitherto unexplored strategic potentialities of blockchain, a technological innovation, for ODL could be explored adequately.

Findings - The findings of the paper reveal that ODL must not miss out on the opportunity of harnessing the hitherto unexplored strategic potentialities of blockchain in its quest of attaining and sustain competitiveness vis-a-vis conventional system of learning. Results of this study sufficiently hint at the possible viability of considering blockchain as a strategic resource for ODL.

Practical implications - Results of this study sufficiently indicate the possible viability of considering blockchain as a strategic resource for ODL which in turn make them significant for decision-makers and policymakers engaged in developing ODL. Findings hint that ODL needs to make efforts to harness the strategic potentialities of blockchain for attaining and sustaining competitiveness which would also be helpful for ODL to contribute towards achievement of sustainable development goals. This paper attempts to provide a strategic viewpoint to the use of this technological innovation as a significant intangible resource discussing primarily the strategic perspectives of blockchain helpful in the further development of ODL.

Originality/value - Although uses of blockchain-enabled applications in ODL are relatively new, the growth is very fast. The present paper offers originality and value by filling the gap created by the inadequacies of studies focusing on the idiosyncratic characteristics including but not limited to decentralization and security of blockchain. Findings suggest that blockchain offers huge potentialities in terms of benefits for entire ODL ecosystem comprising different stakeholders such as institutions, learners, educators, etc.
\end{abstract}

Keywords Blockchain, Competitive advantage, ICT, Innovation, Intangible resources, ODL, Strategic resources

Paper type Conceptual paper

\section{Introduction}

With the advancements in information and communication technology (ICT) and technological innovations, the learning ecosystem has transformed immensely facilitating the open and distance learning (ODL) system in providing education anywhere anytime meeting the changing learning requirements in modern society (Kant, 2019; Nayak et al., 2020). ODL, in recent times, has successfully occupied a well-recognized place in the educational landscape drawing increasing numbers of learners belonging to different backgrounds (Nayak et al., 2020). Nonetheless, the ODL system has not been immune to the risks and challenges associated with lack of trust and accreditation leading to undesirable consequences. ODL which itself is an educational innovation built around sound pedagogical

(C) Nikhil Kant and Kumari Anjali. Published by Emerald Publishing Limited. This article is published under the Creative Commons Attribution (CC BY 4.0) licence. Anyone may reproduce, distribute, translate and create derivative works of this article (for both commercial and non-commercial purposes), subject to full attribution to the original publication and authors. The full terms of this licence may be seen at http://creativecommons.org/licences/by/4.0/legalcode
Blockchain as a strategic resource for

Received 2 September 2020 Revised 3 October 2020 Accepted 6 October 2020

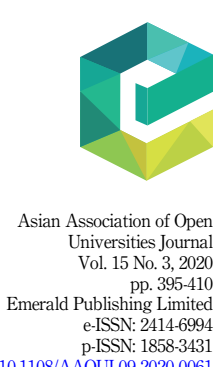

D-ISSN: 1858-3431 
AAOUJ 15,3

396 principles harnessing the power of technologies (COL, 2020), in previous several decades, has thrived substantially. Optimum utilization of the technological innovations, helpful in addressing different challenges such as access, are said to be one of the main reasons behind its massive success, helping it present itself as a feasible alternative of capacity building (McQuaide, 2009).

COL (2020) has amply highlighted its potential of assuming the physical presence of teachers and learners in the same space at the same time and continuance of teaching learning even at the time, when there is a pandemic, conflict, floods, fires or some other disaster. It has recently been noticed and appreciated that open universities and open schools could still remain open, while other institutions were closed as a result of the pandemic (COL, 2020). At the same time, it is being largely perceived that the cross-country and cross-industry emerging technology, i.e. blockchain possesses immense unexplored potentialities of augmenting the competitiveness for ODL due to its idiosyncratic attributes and advantages, much more than conventional system of learning (Kant, 2020).

Blockchain popularly known as the core technology and backbone of the crypto currency, having been used successfully with its applications in the commercial and industrial fields since its emergence only a decade ago, has started to fetch increasing interests of universities (Grech and Camilleri, 2017). This emerging technology is likely to influence ODL also with its untapped potentials, as institutions in ODL system, similar to any other organization, also endeavor to secure competitiveness in the educational marketplace, for which they tend to offer either cost effective or differentiated products or a combination. The emerging use of technology for learning means setting a foundation for new ways of thinking about teaching and learning. By using appropriate technology, ODL provides many enabling opportunities to enable learning for a new role for teachers and for learners with plethora of expectations. The teachers need two basic skills beyond their subject knowledge, i.e. basic technology skills and comfort with tech-tools and pedagogical practice aligned with more meaningful student centered learning. They must try to do so with the help of enhancement of their capabilities of combining tangible and intangible resources. Competition in the ODL environment too has immensely increased, as innumerable learning institutions have emerged in addition to already serving institutions with similar objectives after the introduction of liberalization, privatization and globalization (Kant, 2019).

Noorani (2014) emphasizes on the dire need for organizations to continually look out for newer tools/services/approaches to attain greater competitiveness. Recent technological innovations representing much-hyped Industry 4.0 have brought forward emerging technologies such as blockchain, artificial intelligence (AI), Internet of Things (IoT) and machine learning (ML), possessing huge potential to disrupt our routine life substantially. Out of these emerging technologies, blockchain which is commonly construed as a digitally distributed ledger has started to affect our day-to-day life (Bayyou, 2019; Herian, 2018; Kant, 2020). It is being perceived to be the next potential disruptive technological innovation which can have lasting effects on ODL also which should be ready with the formulation of appropriate strategy to use it suitably for creating and sustaining competitiveness, as it is being considered as a robust product deriving authority and legitimacy promising introduction of enhanced transparency (Kant, 2020; Pasquale, 2015).

The available literature has consensus on the contributions of innovations in attaining competitiveness. Weerawardena and Mavondo (2011) emphasize the shift of attention towards technological innovations in recent times, which as intangible resources are considered in the discussions of strategic management more strategically significant than tangible ones (Barney, 1991; Hitt et al., 2001). Given that an invention yet to prove its commercial utilization cannot be considered an innovation, ODL institutions need to explore how to apply blockchain as a strategic resource to address the challenges, problems and weakness by harnessing the untapped potentials of its dynamic developments in view of 
future trends. ODL can utilize it for empowerment of learners and encourage the idea formulation for free society benefitting the learners and ODL institutions through its adoption. Blockchain is likely to disrupt educational environment by means of innovations arising from the digital transformation of educational and social perspectives (Lévy et al., 2018). However, the need for appropriateness evaluation vis-à-vis the use cases for adoption of solutions provided by blockchain should not be ignored (Lo et al., 2017).

Casino et al. (2019) highlight that the number of its suitability evaluation frameworks is very small developed in the scientific literature. Utilization of blockchain by ODL strategically, as a significant intangible resource considering it an innovation or the best fitted technology, has not been explored in extant literature. The prevailing situations too are not so much clear, as its stakeholders are not sufficiently aware of its advantages and potentials. The main reason behind this lack of clarity is that blockchain and its applications in learning are still emerging and are in embryonic phase. The issue of strategic potentialities of blockchain for ODL facing inadequacy of relevant published literature at a time when blockchain itself is in embryonic phase; this study discussed the unexplored strategic potentialities of blockchain as an intangible resource for ODL to attain and sustain competitive advantage by creating a more learner-centric learning ecosystem. To that end, the paper attempts to briefly inform about the materials and method employed in the next section, followed by the sections presenting an abridged account of idiosyncrasies of blockchain and the emerging trends in ODL. The subsequent section discusses the strategic potentialities of blockchain for ODL, considering it as a significant intangible resource of competitiveness meeting the expectations of different stakeholders before culminating into the section presenting a brief on the limitation and concluding remarks. The paper will be of significant use for decision-makers and policymakers engaged in the development of ODL.

\section{Materials and method}

While it is yet be seen whether ODL would get benefited by the adoption of blockchain, the issue of exploring its strategic potentialities it is perceived to offer does not have underpinnings of adequate relevant literature. The objective of this paper is to discuss this issue to explore its strategic potentialities in for ODL considering blockchain as a resource of competitive advantage. For the purpose of meeting this objective, the paper attempts to deliberate and review various aspects related to adoption of blockchain in ODL to present how and to what extent blockchain can help it in gaining and sustaining competitive advantage in the much-hyped fourth industrial revolution era. Considering that the focus of the paper is more on the economy of the ODL than the implications from a pedagogical standpoint and also that utilization of blockchain by ODL from a strategic angle are still emerging and are in embryonic phase, this study was conducted using qualitative research design considering it to be the most pragmatic. The research design included desk research employing primary sources to cover various related aspects. Desk research refers to the secondary data collection from various sources without fieldwork including but not limited to internal sources, Internet, libraries, government agencies and published reports. A desk research is preferred at the beginning stage of a study to justify more costly primary research ahead. Desk research is known as a review of the relevant related information available before conducting any in-depth study intended to help researchers in building a good understanding of the situation, its evolution and to reveal data gaps in the previous research. Desk research is known as a time and resources saving method which helps in clarifying the context of primary data research, in formulating appropriate research questions and instruments and in verifying the baseline information to understand changes arising from a given intervention (WFP, 2003). Further, the research design included literature review covering any published study with relevance to the objective of the study which also included 
AAOUJ 15,3

398

Figure 1.

An elementary idea of blockchain

studies focused on applications of blockchain in general, in addition to ODL. The review of the literature covered published reliable literature on blockchain related to its applications in the educational ecosystem and also several successful cases.

\section{Blockchain: idiosyncratic attributes and advantages}

Emerging technology of blockchain and its applications are being considered to possess substantial capabilities of affecting our daily life through disruption of traditional products and services, having gained immense popularity through bitcoin and other cryptocurrencies. Blockchain is being perceived to handle big data maintaining security and transparency enhancing trust and transparency because of idiosyncratic attributes of records permanence and smart contracts. This technological innovation is considered to be one of the most influential one, having emerged in the previous decade, which education sector must use to get benefitted by employing its unique features for improving the teaching-learning process and collaborations among different stakeholders (Bayyou, 2019; Kant, 2020).

Nakamoto (2008) defines blockchain as a distributed peer-to-peer linked-structure, also underscoring its utility in solving plethora of problems associated with the maintenance of the transactional order and eliminating double-spending. Grech and Camilleri (2017) highlight its idiosyncrasies by stating that blockchain is a distributed ledger of recording shareable information such as transactions, identities, contracts, assets or any other digitally described thing amongst the community members with the mechanism of copying on all network-connected computers, and the members thus maintain own data collectively validated by almost all of them and view complete transactions history because of the permanence, transparency and search-ability of these data.

An elementary idea of blockchain presented in Figure 1 suggests that a "block" in the blockchain represents the addition of the update to the tail of "chain" taking recourse to the entries and edits which get initiated, validated, recorded anddistributed by a protocol. The "block" is a fixed structure which makes use of cryptology to remove requirement of an intermediary as the trust-keeper relying on complex algorithms run by participants to certify system integrity.

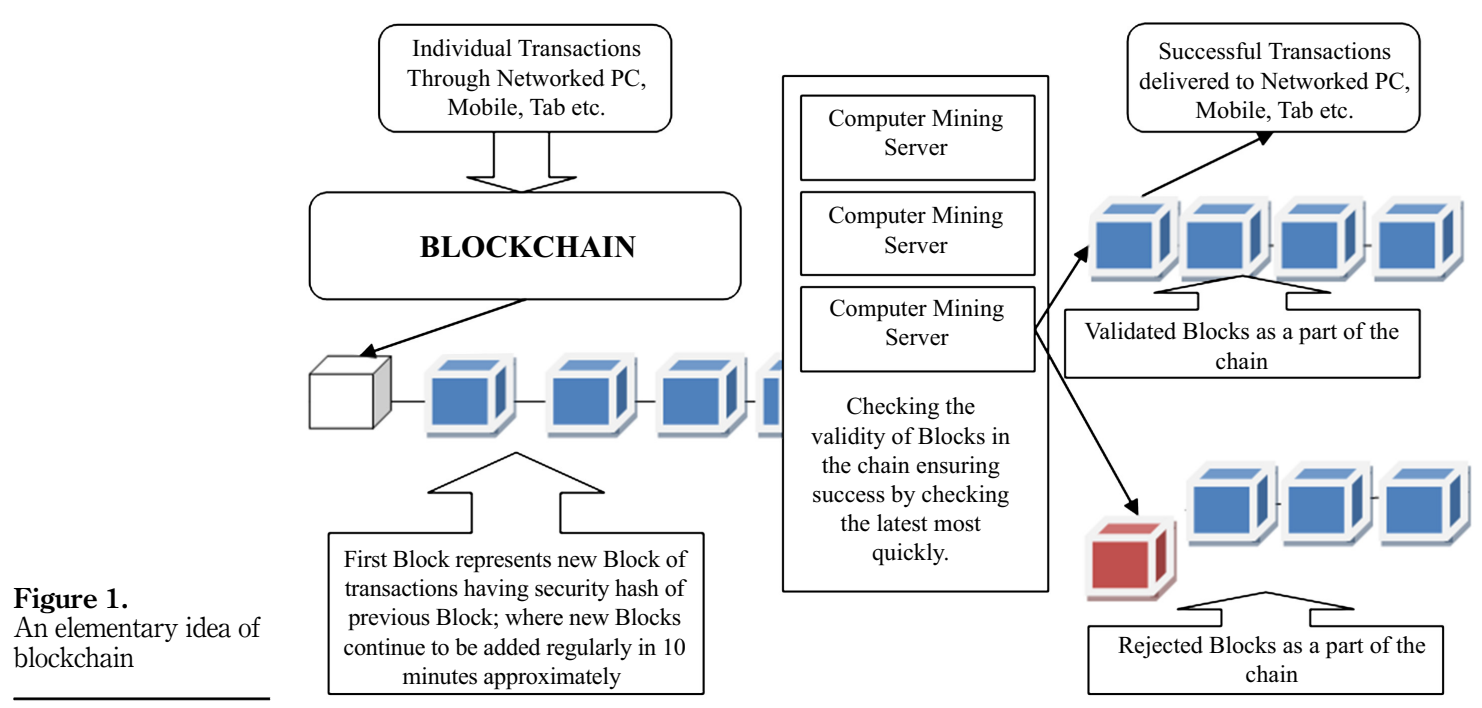


Nakamoto (2008) posits that the distribution and consensus algorithms in blockchain is achieved with the help of "Proof of Work", a verification mechanism which uses time-stamping of data on blockchain demonstrating it as an idiosyncratic attribute of the continuously growing chain. Chen et al. (2018) argue that blockchain has four idiosyncratic attributes which are decentralization, immutability, traceability and currency properties stressing that these idiosyncrasies build capability of bringing about a set of advantages (see Table 1).

Relevant studies have primarily focused on its uniqueness highlighting its privacy and security related features (Casino et al., 2019), considering that organizations assembling vast personal data including sensitive information can get benefitted immensely by using blockchain in enhancing the security aspects of big data (Puthal et al., 2018). Hou (2017) highlights its uniqueness on the basis of its disintermediating transactional and record keeping attributes hinting at its capabilities of transforming the operational ways of local governments. The arguments by Casino et al. (2019) favour him by underlining the targets of blockchain governance of offering similar services with more efficiency without compromising validity by following a decentralized mechanism. Casino et al. (2019) also highlight it as a reinforcing tool for bringing about equality and equal opportunities in providing such public services to worldwide citizens without presence of any third-party intermediation. Boucher (2016) showcases its utility in e-voting by making the voting processes faster, simpler and cost effective strengthening democracies gaining favour from Noizat (2015), who supports relying on its open-source, peer-to-peer, decentralized and independently verifiable network for confidence building of the stakeholders including voters. Umeh (2016) too supports by mentioning the increased interests of the corporations beyond sectoral affiliations in blockchain by looking out for the huge opportunities with respect to digital transformation and solutions to real-life problems. Nonetheless, Casino et al. (2019) present the waste of mining network resources as its primary limitation, leading to more energy consumption and concerns in applying its computational power. It is notable that its role has been highlighted in helping achieve sustainable development (Nguyen, 2016) with the increased use of renewable energy (Potenza, 2017), too. Casino et al. (2019) too indicate the growing interest of academic communities in blockchain-enabled applications, who further showcase a future research roadmap including three main research streams namely avenues, challenges and opportunities, reminding that no review at this stage could be adequately exhaustive when this novel technology witnesses continuous fast paced growth.

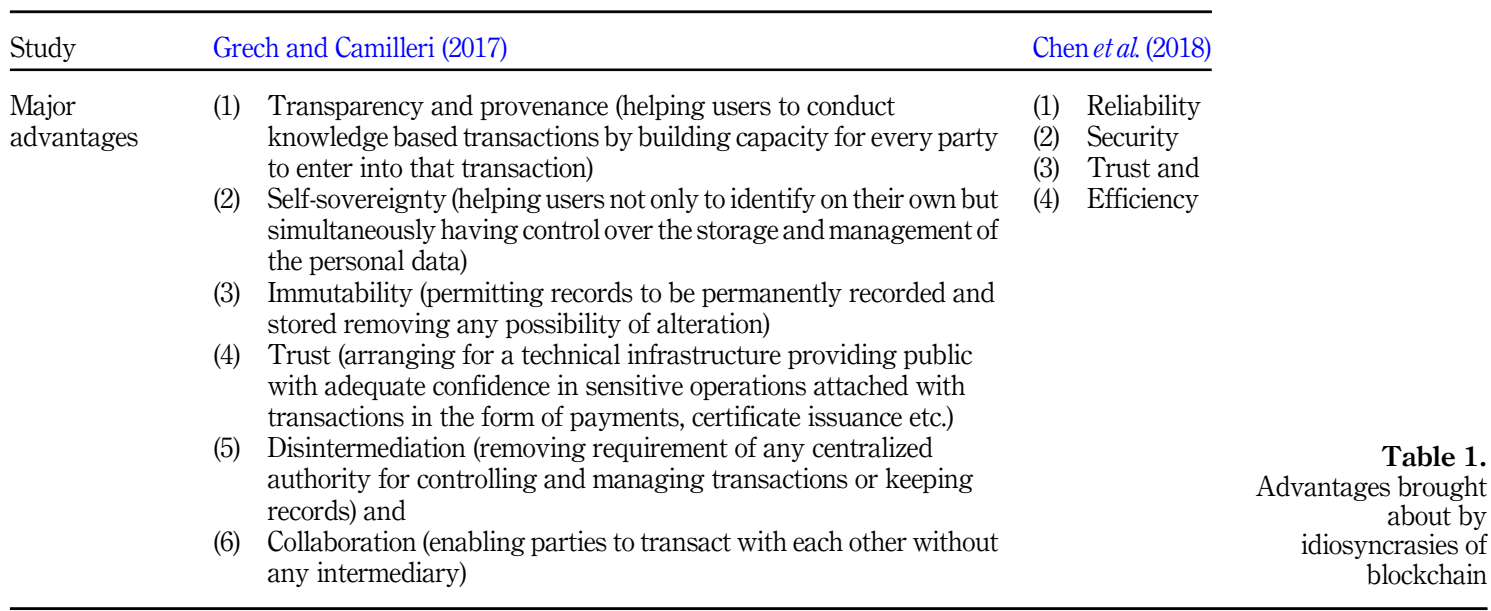


AAOUJ 15,3

There are ample studies which have focused on its disruptive potential considering it a significant source of innovations leading to process improvement, optimization and automation emerging in the form of blockchain based e-business models; find Casino et al. (2019) which receives support from IBM Corp (2016), which informs that it apparently enhances commercial performances and opportunities and helps save cost and time also. Underwood (2016) highlights the applications potentialities of blockchain underscoring the presence of immutability, transparency and trust in every transaction of blockchain considering it as an innovative technological development which receives underpinnings from Zhu and Zhou (2016), who argue that by virtue of these idiosyncratic attributes it can propagate transparency, data security and integrity, data management decentralization, tamper-resistance, anti-forgery, efficiency, flexibility, reliability and without any risk of centralized failure, which have helped it expand popularity, beyond the only recognition of being the technology underpinning crypto currencies such as Bitcoin, in other sectors than finance. Casino et al. (2019), however, clarify that its individual features might not appear to be idiosyncratic in view of integration of popularly known mechanisms but their combinations make it unique. They also posit that with the maturity, its usefulness is bound to draw more interest by different industries which would require customization as per real requirements. While Zhao et al. (2016) favours its growing relevance, IBM Corp (2016) reports the declaration of majority of its $\mathrm{C}$-suite executives regarding their active engagement with blockchain. It is notable that developers and researchers have already started to gather as much information and be ready to exploit its huge potentialities in different sectors (Christidis and Devetsikiotis, 2016).

\section{ODL: the emerging trends}

Preceding several decades have witnessed the emergence of ODL as an effective mode of learning with the "Teaching to Learning Facilitation to Facilitated and Supported Enquiry" induced learning paradigm shifts (Brown, 2006), on a continuum with the very basic correspondence form at one end to the newer forms using emerging technologies at the other, catering to the continuously escalating needs of the learners in ODL system. Its distinctive characteristics have brought about huge expansion by attracting large current and potential learners, with the accelerated utilization of technological innovations and effect of globalization of educational institutions, which have also brought various challenges related to accreditations, collaborations, quality, digital divide, equity and human rights to be addressed through adoption of proactive approaches (Jung, 2005) by ODL, which has emerged as a possible substitute of conventional learning system already faced with quality related challenges due to overloaded classrooms (Ural, 2007).

ODL representing educational process with utmost teaching and communication falls back upon artificial print/electronic medium to bridge the time and space gaps between educators and students (UNESCO, 2002). ODL faced with the competition from the conventional mode of learning considers technological innovations important for improving its effectiveness by developing certain role-specific competencies in the era of much hyped fourth industrial revolution, which underscores that innovative technologies can significantly transform the delivery mechanism of instructions and materials to ODL learners along with the theoretical and practical trainings to educators for their own growth and survival also (Brenner, 2007; Kant, 2020). However, open universities need to be prepared to compete with local and foreign universities at the same time by equipping themselves technologically to exploit access and flexibility-related strategic advantages of technological developments (Tait, 2018). Bordoloi (2018), emphasizing the need for establishing greater access, equality, quality and expansion for ensuring inclusive growth, underscores that ODL 
institutions need to be comfortable with technological developments to facilitate and strengthen the higher education system in developing countries such as India harnessing its capability of providing quality and affordable education at the learners' doorsteps. COL (2020) emphasizes on the findings of the research highlighting the significant contributions of ODL in the education sector in enhancing access and quality, improving support for inclusion, reducing costs and also the carbon footprint. India with a lower higher education GER of $24.5 \%$ only (age category of $18-23$ years) at a time when developed countries have achieved $90 \%$ or more, sees silver lining in the capacity of its ODL system having current enrolments of $12 \%$ of the total enrolments higher education demonstrating substantial contribution in GER and huge potential of imparting education to the learners in disadvantaged communities (MHRD, 2016). IGNOU, an apex ODL institution in India, has been able to attain leadership position with the help of optimum utilization of technological developments and innovations for improving satisfaction of learners realizing appropriately the mammoth dependence of recognition of ODL on learner-centric flexible approach, which has also helped IGNOU acquire the status of a guiding body for ODL institutions (IGNOU, 2020).

COL (2020) informs that universities providing teaching-learning through ODL cater to in excess of $4.4 \mathrm{~m}$ learners alone in the Commonwealth. Wolcott (2003) emphasizes the support garnered by developing countries, such as India, from the growth of ODL to achieve expansion of higher education to every nook and corner in order to impart appropriate learning utilizing technological developments in an effective and efficient manner as they facilitate greater flexible and interactive learning experience. Maximum governments in the Asia-Pacific region, a region which boasts of actively enrolled degree-level students in excess of $0.1 \mathrm{~m}$ in as many as seven mega universities, have preferred ODL because of its tremendous potential (Jung, 2005) anticipating it to be of immense help in leading them to transform for securing sustainable development (Siaciwena and Lubinda, 2008). Nonetheless, COL (2020) emphasizes the need to promote, develop and implement technology-enabled learning policies and strategies considering lack of adequate access to computers and Internet connectivity as the biggest obstacles, advocating for suitable deployment of affordable technologies to ensure last mile access and develop blended learning environments as per the needs of learners by means of appropriate online systems for the purpose of achieving expected learning outcomes.

\section{Strategic potentialities of blockchain for ODL}

Organizations strategizing to gain favourable results and competitiveness with their competing abilities try to harness their agility in executing suitable strategy to improve efficiency and effectiveness and implementing resources better than competitors which include not only assets and capabilities but also the processes, attributes, information and knowledge mainly (Barney, 1991; Bharadwaj, 2000; Peteraf, 1993; Porter, 1980, 1985). Barney (2001) further elaborates that competitive advantage denotes the skills, capabilities and methods to use resources for the purpose of outcompeting rivals. Nonetheless, these resources emerging over time from internal activities or external acquisition or a combination of both can not only be tangible but also intangible. Intangible resources are found to be more strategic being inimitable (Barney, 1991; Hitt et al., 2001). They primarily include trademark IPRs, patents, copyright, logo, contracts, trade secrets, designs, databases, know-how, collective attributes, etc. which along with tangible resources add economic value (Barney, 1991; Reed, 2005; Schriber and Löwstedt, 2015). Resource based view (RBV) emphasizes the significance of the idiosyncratic attributes, namely value, rareness, inimitability and nonsubstitutability (VRIN) of resources to sustain competitive advantage (Barney, 1991), which is achieved using the generic strategies of cost leadership, differentiation, focus on a 
AAOUJ 15,3

402

segment using either of the first two (Porter, 1980). Teece (2007) further highlights the significance of dynamic capability through dynamic capabilities view (DCV) in strategic management in terms of integration and reconfiguration of external and internal resources in order to sense threats/opportunities, to seize them and to reconfigure according requirements for sustaining competitiveness harnessing the potentials of timely responsiveness and rapid and flexible innovations.

Taking a cue from "When the software is not an integral part of the related hardware, computer software is treated as an intangible asset” (IND AS, 2015, p. 1,112), the code-based technology and hardware reliant blockchain, lacking any central controlling part and existing on multiple computers networked but not integrated with any hardware, presents itself to be eligible for being considered as an intangible resource. ODL having emerged as a new teaching model can intend to attain competitiveness configuring, utilizing and making adequate uses of utility of resources harnessing its potential of helping people providing them with the alternative to learn and teach anytime/anywhere with the underpinnings provided by developments related to multimedia and technology (Faridi and Ouseph, 2014) such as blockchain. Here, it is notable that the stiffness of competition in this era of liberalized, privatized and globalized world has increased immensely not only in the conventional system of learning only but in ODL system also with the increased presence and emergence of

Figure 2.

Blockchain in ODL institution: an overview

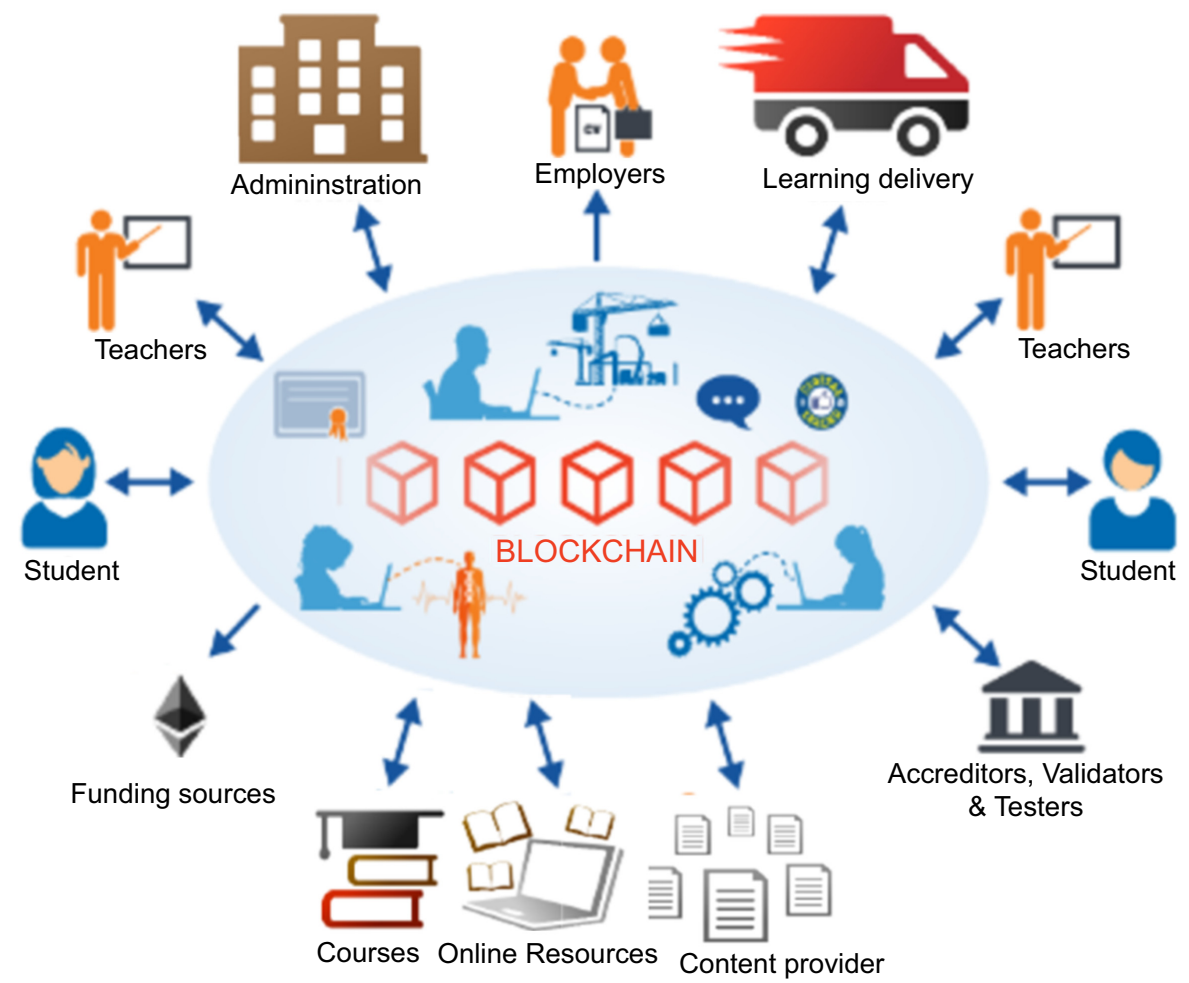

Source(s): Adapted from Mikroyannidis et al., (2018); and https://blockchain.open.ac.uk/about/ Retrieved May 21, 2019) 
institutions with similar objectives. Figure 2 presents an outline of the uses of blockchain in a Blockchain as a simple transaction system of an ODL institution to make picture clearer.

Bdiwi et al. (2017) argue in favour of the greater benefits for the omnipresent learning environments where blockchain can help solve the problems related to vulnerability, privacy and security; Grech and Camilleri (2017) related to digital accreditation of the learning and $\mathrm{Xu}$ et al. (2017) related to enhancement of the certificate management with greater digital infrastructural data security and trust, underlining its idiosyncrasies.

The recent times have witnessed an increasing number of blockchain-enabled applications for the purpose of addressing different educational problems. One such example is blockcerts which was used by the MIT Media Lab to issue digital certificates from the year 2015 to learners in a community providing them with more control over own certificates eliminating any need of a third party verification (Jones, 2017). This is high time that ODL explored the strategic potentialities of blockchain, as it cannot afford to ignore the opportunities of embracing and risks of ignoring it in the much hyped era of Industry 4.0. There is a need to emphasize the replication in the ODL to attain competitiveness of the efforts of institutions such as Woolf University, which has regulated registration/payments, facilitated academics for advertising their expertise to the prospective learners permitting them also to select appropriate programmes as per their needs and interests using "smart contracts" embedded in blockchain, which can help eliminate the requirement of physical premises and cumbersome administrative processes by resulting into substantial costs reduction along with the differentiation in the form of improved digital platform openness for academics for joining it and offering different academic services also (Mikroyannidis et al., 2018).

Blockchain, with the perceived disrupting capability by virtue of record-keeping of timestamped transaction, has been adopted by the Oxford academics for launching world's first "Blockchain University" motivating other higher education institutions for using blockchain. It is using blockchain to assist learners to get appropriate funding entities to complete education, to give away tamper-resistant digital certificates verifiable and shareable with the employers without any compromise with safety and security. Another premier institution MIT has also started using it indicating that activities including but not restricted to award of degrees, recordkeeping, accreditation, licensing, IP management and payments are likely to be disrupted by blockchain, which is yet to be harnessed excepting a few already using it successfully (Grech and Camilleri, 2017) in the ODL such as Knowledge Media Institute (KMI) at UKOU, which has successfully used it for registration and verification of academic records of huge number of learner reducing cost and offering differentiation in the form of enhanced validity of certificates.

There are several other cases which can be considered useful for strategically using blockchain-enabled applications such as CredenceLedger, a permissioned blockchain-based platform, used for decentralized academic credentials verification employing blockchain ledger technologies for storing their compact data proofs with the protection of blockchain's inherent security attributes which can be verified by any stakeholders including third-party intermediaries easily (Arenas and Fernandez, 2018). An another credit platform EduCTX, a derivative of the open-source Ark Blockchain Platform, used ECTX tokens as a representative of the credits of the course completed by the learners giving a distributed as well as interoperable processing, managing and controlling architecture model for the credits which can be used in ODL for an enhanced access to updated data of the learners, whereas the learners would benefitted by the permission for an enhanced transparent and unified view of the courses accomplished by them (Turkanovic et al., 2018).

Lifestyles, norms and activities are transformed by innovative technological developments with the effect on not only the process of learning, teaching, research but also on the instructional patterns, style, technique tools in ODL by increasing their 
AAOUJ 15,3

404

challenges, but technological innovations such as blockchain have the strategic significance for ODL by virtue of their potentialities with respect to better management, administration and delivery mechanisms assessable by imagining a learner's satisfaction coming from having earned a blockchain-powered digital certificate with an innovative learning experience and higher visibility of accomplishment in amongst employers. This enhanced satisfaction can attract more learners to such ODL institutions, where the satisfied learners with their positive perception can help these institutions improve performance in future (Cavanaugh, 2005) by means of enhanced reputation of a progressive institution helping it in collaborating with pioneers for research and development.

Chen et al. (2018) stress on the idiosyncrasy of blockchain in making available a reliable balance to measure the processes and outcomes of learning for the stakeholders underscoring its VRIN attributes visible through information symmetry and trust emerging from decentralization, immutability, traceability and currency properties embedded in it, which can help ODL remove institutions from the middle of educators and learners. Kant (2019) argues that ODL needs to make strategic efforts for attaining competitiveness through optimal resource utilization using core competencies arising from locational advantages, usage of ICT, reputations and differentiated learning materials to meet the continuously increasing demands of other stakeholders than learners only, as ODL has various complementing and interacting stakeholders.

It is notable that while ODL educators do possess added capabilities for utilizing emerging technologies properly presenting themselves as key actors for instructions delivery, their training requirements need to be relooked for effectively and efficiently using blockchain which can affect communication and interaction styles immensely. Nonetheless, the fast transmitted feedbacks in the blockchain-enabled learning ecosystem from different stakeholders on a real time basis would improve the market scalability and industrial interface in addition to the learning and instructions delivery quality, which can escalate the demand for unique educational products and services offered by these ODL institutions. ODL institutions need to adapt at a faster pace while catering to the educational needs of a more varied group of learners and other stakeholders than conventional mode of learning. While learners and educators can enjoy greater ownership of the complete learning process with the use of blockchain without compromising the quality/accessibility/security, transferring the complete controlling authority of their personal data to learners can enhance affordability while enhanced records management of learning activities/assessments/feedbacks/ certificates, etc. using blockchain can offer cost effectiveness as well as differentiation to ODL (Kant, 2020). COL (2020) stresses upon the mammoth contributions of ODL institutions in the last five decades in providing quality teaching-learning offered in an open and distant manner by means of the optimum utilization of a range of technologies, cautioning at the same time that despite these technological developments opening new possibilities, solutions need to be customized to specific contexts.

COL (2020) underscores the need for ODL institutions to remain connected with teachers and learners regularly making the best use of technological innovations demonstrating proactivity in adapting to the dynamically changing environment by taking advantage of online and offline learning opportunities. Chen et al. (2018) further highlight that blockchain can not only be helpful for tutors and learners to evaluate instructional design and delivery but can improve the motivation of its learners by virtue of record keeping of educational activities, processes and outcomes in a reliable and trustworthy style in addition to educators' performance for making their appropriate assessments. It can also empower learners by strengthening the idea of a free society for learners as well as learning institutions by using its applications related to permissions to members of securing their own transactions settlement, receipt andtransfer of assets in an affordable manner saving them huge cost on activities primarily related to award of degrees, administration and management, accreditation, 
licensing, recordkeeping, IPs, fee, grants, fellowships andsubsidies payments (Tschorsch and Scheuermann, 2016). ODL institutions can also replicate the successful implementation by premier institutions such as University of Nicosia (UNIC) accepting tuition fee in Bitcoin, to achieve cost effectiveness and efficiency in the finance, administration and management especially for calculating scholarships, salaries, grants, etc. (Kant, 2020).

ODL institutions can effectively use smart contract embedded in blockchain to manage the challenges with respect to evaluation and formative assessment through detailed teaching and learning record keeping records facilitating learners to use unique account for submission of their work for the review on the learning platform for results to be stored in "blocks" (Chen et al., 2018). The educators' instructions delivery in the ODL cannot be improved on the basis of evaluation based on the learners' feedbacks received conventionally because of their biasness. These challenges can be overcome by using instruction evaluation indicators such as recording of teaching in real time, verifying consistency of teaching designs and practices, submitting instructional activities, etc. with the help of verifiable and supplementary smart contracts engaging educators and learners to receive rewards as a token of appreciation/encouragement issued by institutions in the form of digital currency (Chen et al., 2018).

COL (2020) underscores the need to develop and deploy a secured system of storing and transferring credentials using blockchain or other similar technologies for ODL institutions. Validity of certificates can be verified by users themselves without contacting the issuers in a system enabled by blockchain which removes the intermediary (Grech and Camilleri, 2017), thereby decreasing the cases of fraud due to adequate checking/validation of the users' ID (Chen et al., 2018). Grech and Camilleri (2017) hint at the disrupting capability of blockchain in the realm of learners' information systems as well as dominance of existing players in education and can immensely reduce the data management costs in ODL by proposing users' increased personal data ownership and control in the data management Grech and Camilleri (2017) further stress on its potentialities for ending the use of paper for degrees/credits transfer due to permanent movement of records on a reliable secured blockchain with encryption for their automated recognition ensuring their storage and verification throughout life also facilitating lifelong learning. Such activities minimize the chance of loss and falsification of paper documents, and thus can be immensely helpful for ODL institutions in maintaining integrity and transparency of the database utilized as a one-stop source of facts for any kind of inquiry and verification, for all practical purposes.

ODL can seek help from the implementation of "learning is earning". It can help manage factors which are responsible for the undesirable learning outcomes such as lacking motivation, financial constraints, etc. with the effective use of blockchain (Sharples and Domingue, 2016), offering real-time awards to learners as digital currency stored in education wallet which they can use later for fee payments. The updated record keeping on blockchain of entire learning can also prove to be immensely helpful for the potential employers while offering jobs. It can help match the desired skills reducing the wastage of time/resources of employers and job seeking learners both (Chen et al., 2018) considering that learners having made more educational payments through such digital currency are more talented and are therefore eligible for more appreciation/easier educational funding, thereby proving helpful in talent investment (Chen et al., 2018).

Chen et al. (2018) posit that smart contract might help reduce intermediary costs in transactions with improved reliability in a secured encrypted technological ecosystem executing the code initiated on every rule-breaking paving way for termination of smart contract. ODL educators and learners, therefore, can use this in their learning experience for the purpose of eliminating many educational issues harnessing its embedded executive powers and fairness for online execution and storage of agreements. 
AAOUJ 15,3
Adoption of flexible programmes' and educational institutions' accreditation and approval processes resorting to online validation processes reducing visits of peer teams has been stressed upon by COL (2020). Grech and Camilleri (2017) also underscore that ODL can also be benefitted if the accreditation/quality assurance bodies start using blockchain for issuing licenses and certificates for ODL institutions which become simultaneously available in public domain to be used by different users for verification on their own. In addition, using blockchain can facilitate ODL in removing any need of centralized database managing authority for the management of IPs with respect to recordkeeping of first publication and its citations, and OER use/re-use (Grech and Camilleri, 2017).

Despite all these advantages, there is a need to be aware of the hype around blockchain enticing people for using it wrongfully in problem-solving (Brenner, 2007; Kant, 2020) along with the level of understating resulting into major failures due to inflated expectations (Iansiti and Lakhani, 2017). It is, however, notable that studies such as Casino et al. (2019) have clarified that it ought not be considered a hype any longer in view of the greater attention being paid and higher investments being made by the corporations in blockchain perceiving its huge potentialities. Given its more rapid growth in usage than other technological developments in recent past, lack of suitable regulatory and monitoring mechanism for blockchain ecosystem ensuring proper accountability and protection of the stakeholders' interests also needs to be accounted for. Further, issues such as requirement of "Proof of Work" consensus cause enormous energy wastage in addition to very slow rate of transactions per second affecting performance (Vukolić, 2016) and thus prove to be costly to ODL, which has already been overloaded with massive fixed assets investments. Here, it is notable that not only the technological advancement adoption but also the politico-economic factors affect immensely ODL (Carter, 2009), which make the learning process/behaviors/ outcomes in ODL complex requiring their subjective reviews necessarily requiring human intervention practically uncontrollable by the automated blockchain. Nonetheless, ODL ought to demonstrate greater foresight to consider the strategic potentialities of blockchain as an intangible idiosyncratic resource with VRIN attributes. It might help ensure adequate skill up gradation of learners sensing the underlying transformation from coordination to cooperation to collaborative approach giving proper emphasis to the powers of stakeholders for meeting its strategic objectives and goals (Faridi and Ouseph, 2014).

\section{Limitations and conclusion}

Review of the literature suggests that there is inadequacy of relevant studies explaining the strategic contributions of blockchain in ODL. Blockchain is perceived to possess ability to provide solutions to many problems which could not be solved otherwise because of its possession of various idiosyncratic attributes and disrupting capabilities with respect to any centralized system which coordinates information (Davidson et al., 2016). It is notable that the demand of the objectives of the study was to keep technical details of blockchain adequately simplified intentionally for easy comprehension by any reader with little technical background. Further, the intention to focus primarily and mainly on the strategic aspects of blockchain instead of its technical aspects was binding on the authors in view of the purview and boundaries of the objectives which restricted from presenting different technical details (for, e.g. programming and source code) covering programming or product development aspects for ODL.

Blockchain, in recent times, has not only started to affect our routine life but has emerged with the expectations of revolutionizing ODL also through basket of opportunities related to its various activities in order to develop a more learner-centric ecosystem (Kant, 2020). Herian (2018) cautions organizations lagging behind in adopting blockchain keeping in view its 
potentials with respect to changing the global business dynamics by virtue of its idiosyncratic features. The selection process of technology contains the key to competitiveness and therefore, the "problem first-technology second" approach (Vitso et al., 2017) i.e. using knowledge and experience for developing solution, to use blockchain possesses immense strategic potentialities for the institutions in ODL system. ODL educators are to perform roles and responsibilities different from conventional system of learning, which require them to update themselves regularly with specific knowledge and skills to be prepared for performance of varied roles and maintenance of quality to remove the negative notion in the minds of stakeholders as regards ODL where distance educators can get immense support from blockchain for providing suitable guidance with respect to the contents, assignments/projects and their evaluation, etc. to their learners. Academic counseling of the ODL counselors, shouldering great responsibility of helping learners for academic accomplishment, remain partially supervised failing to ascertain the weakness in performance of this role in cases of learners' failure and the same can be monitored adequately through smart contracts embedded in blockchain by ensuring maintenance of records of their academic counseling/ guidance quantitatively as well as qualitatively. ODL educators possessing added capabilities for utilizing emerging technologies properly present themselves as key actors for instructions delivery, and their training requirements need to be relooked for effective and efficient use of blockchain. The fast transmitted feedbacks in the blockchain-enabled learning ecosystem from different stakeholders on a real time basis would also improve the scalability and industrial interface. The learners and educators can enjoy greater ownership of the complete learning process with the use of blockchain. Using blockchain offers cost effectiveness and differentiation related potentialities for ODL. Use of blockchain-enabled applications in ODL at this stage is still in the nascent stage with the limited scope. Nonetheless, further advancements and more uses of blockchain-enabled applications in ODL would create new technological foundations and practical models contributing to an enhanced pedagogy.

With the expenses in instructional delivery and administrative processes continue to increase rapidly, the idea about capabilities of blockchain based on whatever relevant experience educational sector and ODL have gathered, it appears to be offering huge potentialities as a strategic intangible resource possessing idiosyncratic attributes. With these ideosyncrasies, blockchain might prove to be a strategically important intangible resource for ODL if adequate attention is paid to the hype, immature regulatory mechanism, drawbacks and technical issues such as wastage of energy and slow rate of transactions which calls for more studies to reach any logical conclusion.

\section{References}

Arenas, R. and Fernandez, P. (2018), "CredenceLedger: a permissioned blockchain for verifiable academic credentials", 2018 IEEE International Conference on Engineering, Technology and Innovation (ICE/ITMC), Stuttgart, pp. 1-6, doi: 10.1109/ICE.2018.8436324.

Barney, J.B. (1991), "Firm resources and sustained competitive advantage", Journal of Management, Vol. 17 No. 1, pp. 99-120.

Barney, J.B. (2001), "Resource-based theories of competitive advantage: a ten-year retrospective on the resource-based view", Journal of Management, Vol. 27 No. 6, pp. 643-650.

Bayyou, D.G. (2019), "Blockchain technology applications in education", International Journal of Computing and Technology, Vol. 6 No. 11, pp. 68-74.

Bdiwi, R., De Runz, C., Faiz, S. and Cherif, A.A. (2017), "Towards a new ubiquitous learning environment based on blockchain technology", Proceedings - IEEE 17th International Conference on Advanced Learning Technologies, ICALT 2017, pp. 101-102. 
AAOUJ 15,3

Bharadwaj, A. (2000), "A resource-based perspective on information technology capability and firm performance: an empirical investigation”, Management Information Systems Quarterly, Vol. 24 No. 1, pp. 169-196.

Bordoloi, R. (2018), "Transforming and empowering higher education through open and distance learning in India”, Asian Association of Open Universities Journal, Vol. 13 No. 1, p. 2018.

Boucher, P. (2016), What if Blockchain Technology Revolutionised Voting?, Scientific Foresight Unit (STOA), European Parliamentary Research Service.

Brenner, S.W. (2007), Law in an Era of 'Smart Technology', Oxford University Press, Oxford.

Brown, T.H. (2006), "Beyond constructivism: navigationism in the knowledge era", On the Horizon, Vol. 14 No. 3, pp. 108-120.

Carter, D.J. (2009), "Distance education in China and India: collectivism and connectivism", International Review of Research in Open and Distance Learning, Vol. 10 No. 3, pp. 1-7.

Casino, F., Dasaklis, T.K. and Patsakis, C. (2019), "A systematic literature review of blockchain-based applications: current status, classification and open issues", Telematics and Informatics, Vol. 36, Elsevier, pp. 55-81.

Cavanaugh, C. (2005), "Distance education success factors", International Journal of Educational Telecommunication, Vol. 7 No. 1, pp. 1-6.

Chen, G., Xu, B., Lu, M. and Chen, N.-S. (2018), "Exploring blockchain technology and its potential applications for education”, Smart Learning Environments, Vol. 5 No. 1, p. 10.

Christidis, K. and Devetsikiotis, M. (2016), "Blockchains and smart contracts for the internet of things", IEEE Access, Vol. 4, pp. 2292-2303.

COL (2020), Guidelines on Distance Education during COVID-19, COL, Burnaby.

Davidson, S., De Filippi, P. and Potts, J. (2016), "Economics of blockchain”, SSRN Electronic Journal. doi: $10.2139 / \mathrm{ssrn} .2744751$.

Faridi, M.R. and Ouseph, S.N. (2014), "New directions and challenges for ODL: building collaborative business approach", European Scientific Journal, Vol. 1, No. Special, pp. 217-223.

Grech, A. and Camilleri, A.F. (2017), "Blockchain in education", Inamorato dos Santos, A. (Ed.), EUR 28778 EN, doi: 10.2760/60649.

Herian, R. (2018), “Taking blockchain seriously”, Law and Critique. doi: 10.1007/s10978-018-9226-y.

Hitt, M.A., Ireland, R.D., Camp, S.M. and Sexton, D.L. (2001), "Strategic entrepreneurship: entrepreneurial strategies for wealth creation", Strategic Management Journal, Vol. 22 No. 6, pp. $479-492$.

Hou, H. (2017), "The application of blockchain technology in E-government in China", 26th International Conference on Computer Communications and Networks, ICCCN 2017.

Iansiti, M. and Lakhani, K.R. (2017), "The truth about blockchain”, Harvard Business Review, pp. 1-11, available at: https://hbr.org/2017/01/the-truth-about-blockchain (accessed 16 May 2019).

IBM Corp (2016), "Making blockchain real for business. Explained with high security business network service", available at: https:/www.ibm.com/systems/data/flash/it/technicalday/pdf/ Makingblockchainrealforbusiness.pdf (accessed 15 August 2020).

IGNOU (2020), IGNOU Profile 2020, Indira Gandhi National Open University, New Delhi.

IND AS (2015), Indian Accounting Standard (Ind AS) 38 Intangible Assets, Ministry of Corporate Affairs, Govt. of India.

Jones, B. (2017), "MIT has started issuing diplomas using blockchain technology", available at: https:// futurism.com/mit-has-started-issuing-diplomas-using-blockchain-technology (accessed 22 June 2019).

Jung, I. (2005), "Innovative and good practices of open and distance learning in Asia and the Pacific", (Series:Apeid, Unesco Bangkok Occasional Paper Series), Vol. 3, International Christian University, Tokyo. 
Kant, N. (2019), "Competitiveness in ODL from stakeholders' perspective: a review and research agenda", The Turkish Online Journal of Distance Education, Vol. 20 No. 3, pp. 59-72.

Kant, N. (2020), "Blockchain: a resource of competitive advantage in open and distance learning system", in Sharma, R.C., Yildirim, H. and Kurubacak, G. (Eds), Blockchain Technology Applications in Education, IGI Global, pp. 127-152, doi: 10.4018/978-1-5225-9478-9.ch007.

Lévy, W., Stumpf-Wollersheim, J. and Welpe, I. (2018), "Disrupting education through blockchainbased education technology?”, SSRN Electronic Journal. doi: 10.2139/ssrn.3210487.

Lo, S.K., Xu, X., Chiam, Y.K. and Lu, Q. (2017), "Evaluating suitability of applying blockchain", Proceedings of the IEEE International Conference on Engineering of Complex Computer Systems, ICECCS, pp. 158-161.

McQuaide, S. (2009), "Making education equitable in rural China through distance learning", The International Review of Research in Open and Distributed Learning, Vol. 10 No. 1, pp. 1-21.

MHRD (2016), All India Survey on Higher Education (2015-16), Department of Higher Education, MHRD, Govt. of India, New Delhi, available at: http://mhrd.gov.in/sites/upload_files/mhrd/files/ statistics/AISHE2015-16.pdf.

Mikroyannidis, A., Domingue, J., Bachler, M. and Quick, K. (2018), “A learner-centred approach for lifelong learning powered by the blockchain", Conference Paper, Conference: EdMedia + Innovate Learning 2018, Amsterdam.

Nakamoto, S. (2008), Bitcoin: A Peer-to-Peer Electronic Cash System.

Nayak, S.R., Kant, N. and Anjali, K. (2020), "Strategy of using ICT in ODL to disseminate higher education in tribal communities: a case of MP, India", Asian Association of Open Universities Journal, doi: 10.1108/AAOUJ-05-2020-0029.

Nguyen, Q.K. (2016), "Blockchain-A financial technology for future sustainable development", Proceedings - 3rd International Conference on Green Technology and Sustainable Development, GTSD 2016, pp. 51-54.

Noizat, P. (2015), "Blockchain electronic vote", Handbook of Digital Currency: Bitcoin, Innovation, Financial Instruments, and Big Data, pp. 453-461.

Noorani, I. (2014), "Service innovation and competitive advantage", European Journal of Business and Innovation Research, Vol. 2 No. 1, pp. 12-38.

Pasquale, F. (2015), The Black Box Society: The Secret Algorithms that Control Money and Information, Harvard University Press., Cambridge.

Peteraf, M.A. (1993), "The cornerstones of competitive advantage: a resource-based view", Strategic Management Journal, Vol. 14, pp. 179-191.

Porter, M.E. (1980), Competitive Strategy, Free Press, New York.

Porter, M.E. (1985), The Competitive Advantage: Creating and Sustaining Superior Performance, Free Press, New York.

Potenza, A. (2017), “Can renewable power offset bitcoin's massive energy demands?", available at: https://www.theverge.com/2017/12/21/16806772/bitcoin-cryptocurrency-energy-consumptionrenewables-climate-change (accessed 10 February 2020).

Puthal, D., Malik, N., Mohanty, S.P., Kougianos, E. and Yang, C. (2018), "The blockchain as a decentralized security framework [Future directions]", IEEE Consumer Electronics Magazine, Vol. 7 No. 2, pp. 18-21.

Reed, M. (2005), “Reflections on the 'realist turn' in organization and management studies”, Journal of Management Studies, Vol. 42 No. 8, pp. 1621-1644.

Schriber, S. and Löwstedt, J. (2015), "Tangible resources and the development of organizational capabilities", Scandinavian Journal of Management, Vol. 31 No. 1, pp. 54-68.

Sharples, M. and Domingue, J. (2016), "The blockchain and kudos: a distributed system for educational record, reputation and reward", in Verbert, K., Sharples, M. and Klobučar, T. (Eds), Adaptive
Blockchain as a strategic resource for ODL

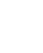


AAOUJ 15,3

and Adaptable Learning. EC-TEL 2016. Lecture Notes in Computer Science, Springer, Cham, Vol. 9891, pp. 490-496.

Siaciwena, R. and Lubinda, F. (2008), "The role of open and distance learning in the implementation of the right to education in Zambia", International Review of Research in Open and Distance Learning, Vol. 9 No. 1, pp. 149-186.

Tait, A. (2018), "Open universities: the next phase", Asian Association of Open Universities Journal, Vol. 13 No. 1, pp. 13-23.

Teece, D.J. (2007), "Explicating dynamic capabilities: the nature and microfoundations of (sustainable) enterprise performance", Strategic Management Journal, Vol. 28 No. 13, pp. 1319-1350.

Tschorsch, F. and Scheuermann, B. (2016), "Bitcoin and beyond: a technical survey on decentralized digital currencies", IEEE Communications Surveys and Tutorials, Vol. 18, doi: 10.1109/COMST. 2016.2535718.

Turkanović, M., Hölbl, M., Košič, K., Heričko, M. and Kamišalić, A. (2018), "EduCTX: a blockchainbased higher education credit platform", IEEE Access, Vol. 6, pp. 5112-5127.

Umeh, J. (2016), "Blockchain double bubble or double trouble?”, ITNOW, Vol. 58 No. 1, pp. 58-61.

Underwood, S. (2016), "Blockchain beyond bitcoin”, Communications of the ACM, Vol. 59 No. 11, pp. 15-17.

UNESCO (2002), Open and Distance Learning: Trends, Policy and Strategy Considerations, Division of Higher Education, UNESCO, Paris.

Ural, O. (2007), "Attidues of graduate students toward distance education, educational technologies and independent learning”, The Turkish Online Journal of Distance Education, Vol. 8 No. 4, pp. 34-43.

Vitso, M., Joar, B., Harkestad, G. and Krogh, S. (2017), “A study on blockchain technology as a resource for competitive advantage", (Dissertation), Norwegian University of Science and Technology.

Vukolić, M. (2016), "The quest for scalable blockchain fabric: proof-of-work vs BFT replication”, Lecture Notes in Computer Science, Vol. 9591, pp. 112-125.

Weerawardena, J. and Mavondo, F.T. (2011), “Capabilities, innovation and competitive advantage", Industrial Marketing Management, Vol. 40 No. 8, pp. 1220-1223.

WFP (2003), Emergency Needs Assessment Methodologies. Non-food Aid Response to Food Insecurity: How Do We Identify the Most Appropriate Types of Intervention through Emergency Food Security Assessments? Ann A in Report of the Technical Meeting: Key Terms in Emergency, United Nations World Food Programme Via Cesare Giulio Viola 68/70, Parco de’ Medici 00148, Rome.

Wolcott, L.L. (2003), "Dynamics of faculty participation in distance education: motivations, incentives, and rewards", in Moore, M.G. and Anderson, W.G. (Eds), Handbook of Distance Education, Lawrence Erlbaum Associates, Mahwah, NJ, London, pp. 549-565.

Xu, Y., Zhao, S., Kong, L., Zheng, Y., Zhang, S. and Li, Q. (2017), "ECBC: a high performance educational certificate blockchain with efficient query", Lecture Notes in Computer Science, (Including Subseries Lecture Notes in Artificial Intelligence and Lecture Notes in Bioinformatics), Vol. 10580, LNCS, pp. 288-304.

Zhao, J.L., Fan, S. and Yan, J. (2016), "Overview of business innovations and research opportunities in blockchain and introduction to the special issue", Financial Innovation, Vol. 2 No. 1, p. 28.

Zhu, H. and Zhou, Z.Z. (2016), "Analysis and outlook of applications of blockchain technology to equity crowdfunding in China", Financial Innovation, Vol. 2 No. 1, pp. 1-29.

\section{Corresponding author}

Nikhil Kant can be contacted at: Nikhilkant25apr@gmail.com

For instructions on how to order reprints of this article, please visit our website:

www.emeraldgrouppublishing.com/licensing/reprints.htm

Or contact us for further details: permissions@emeraldinsight.com 